\title{
Technical note: Improving the accuracy of mid-infrared prediction models by selecting the most informative wavelengths
}

\author{
P. Gottardo, M. De Marchi, ${ }^{1}$ M. Cassandro, and M. Penasa \\ Department of Agronomy, Food, Natural Resources, Animals and Environment, University of Padova, Viale dell'Università 16, \\ 35020 Legnaro (PD), Italy
}

\begin{abstract}
Mid-infrared spectroscopy (MIRS) is widely used to collect milk phenotypes at the population level. The aim of this study was to test the ability of the uninformative variable elimination (UVE) method to select and remove uninformative wavelength variables before partial least squares (PLS) analysis. Milk titratable acidity (TA) and Ca content were used as examples to illustrate the procedure. Reference values and MIRS spectra $(\mathrm{n}=208)$ of TA and Ca were retrieved from an existing database. The data set was randomly divided into calibration ( $70 \%$ of data) and validation (30\% of data) sets, and PLS analysis was carried out before and after the UVE procedure. The UVE procedure selected 244 and 113 informative wavelengths for TA and Ca, respectively, from a total of 1,060 . The elimination of uninformative variables before PLS regression increased the accuracy of MIRS prediction models, and it substantially reduced the computation time. Dealing with fewer variables is expected to enhance the efficiency of MIRS models to predict phenotypes at population level.
\end{abstract}

Key words: mid-infrared spectroscopy (MIRS), partial least squares regression, uninformative variable selection, titratable acidity, calcium content

\section{Technical Note}

Recently, De Marchi et al. (2014) reviewed the application of mid-infrared spectroscopy (MIRS) as a rapid and cost-effective tool for recording phenotypes on a large scale. Mid-infrared spectroscopy has been used to predict milk traits such as fatty acid profile (Soyeurt et al., 2006; De Marchi et al., 2011), body energy status of the cow (McParland et al., 2012), and milk coagulation ability (De Marchi et al., 2013).

Received August 17, 2014.

Accepted February 11, 2015.

${ }^{1}$ Corresponding author: massimo.demarchi@unipd.it
Multivariate calibration methods such as partial least squares (PLS) and principal component regressions are widely used in MIRS analysis. The accuracy of a calibration model is related not only to the quality of gold-standard measurements but also to the quality of wavelength variables and the number of factors used during generation of the PLS model (Li and Jing, 2014). The MIRS spectra contain a huge number of wavelength variables, some of which contain irrelevant information for multivariate analyses. The identification and removal of uninformative spectra regions of a given trait is crucial in reducing computation time in statistical analysis, especially when dealing with large data sets (De Marchi et al., 2014). Currently, MIRS prediction models are developed using PLS regression, and only the spectral regions typically characterized by high noise are removed before PLS analysis (Hewavitharana and van Brakel, 1997; De Marchi et al., 2013).

Several methods for variable selection have been proposed to remove unnecessary or redundant wavelengths from regression models. For example, Leardi (2000) and Ferrand et al. (2011) used a genetic algorithm combined with PLS regression to reduce the number of uninformative wavelengths and improve the accuracy of predictions. Among methods of variable selection, uninformative variable elimination (UVE) based on the analysis of PLS regression coefficients is of particular interest (Centner et al., 1996). The aim of this study was to test the ability of the UVE approach combined with PLS regression to remove uninformative wavelengths and to evaluate the effect of this procedure on the accuracy of MIRS calibration models.

Reference values and MIRS spectra $(\mathrm{n}=208)$ of titratable acidity (TA) and Ca content were retrieved from an existing database of milk samples that were analyzed in 2011. Titratable acidity was determined using Crison Compact D (Crison Instruments SA, Alella, Spain) and expressed in Soxhlet-Henkel degrees $\left({ }^{\circ} \mathbf{S H} / 50 \mathrm{~mL}\right)$ as proposed by Anonymous (1963) in the laboratory of the Breeders Association of Veneto region (ARAV, Padova, Italy). Calcium content was determined after mineralization with nitric acid in 
closed vessels by a microwave system using inductively coupled plasma optical emission spectrometry (full details on the procedure to determine Ca can be retrieved from Toffanin et al., 2015). Spectral information was collected over the spectral range of 5,011 to $900 \mathrm{~cm}^{-1}$ using a Milko-Scan FT6000 (Foss, Hillerød, Denmark).

The same calibration and validation procedures were used for both traits; 10 calibration and validation sets were randomly selected from original data by including $70 \%$ records in calibration and $30 \%$ records during the validation process. Therefore, PLS was carried out 10 times using the ChemometricsWithR package (Wehrens, 2011) of $\mathrm{R}$ software (R Development Core Team, 2006) using an external validation. The statistical analysis consisted of generating PLS models before and after the UVE procedure. In the PLS analysis before UVE procedure, the 1,060 wavelengths were reduced to 520 through the elimination of 2 spectral regions $(1,601$ to 1,717 and 3,052 to $5,011 \mathrm{~cm}^{-1}$ ) that are known to be related to water and thus characterized by a high noise level (Hewavitharana and van Brakel, 1997; De Marchi et al., 2013). The optimal number of principal components used for the evaluation of PLS models was 11 and 12 for TA and Ca, respectively; this number was selected when the lowest root mean square error of prediction $\left(\mathbf{R M S E}_{\mathbf{P}}\right)$ was reached. The coefficient of determination in external validation $\left(\mathbf{R}_{\mathbf{P}}^{2}\right)$, the $\mathrm{RMSE}_{\mathrm{P}}$, and the ratio performance deviation (RPD, calculated by dividing the SD by the $\mathrm{RMSE}_{\mathrm{P}}$ of the trait) were used to evaluate the accuracy of PLS models: in particular, an $\mathrm{R}_{\mathrm{P}}^{2}$ value between 0.83 and 0.90 is considered useful for practical application (Williams, 1987), and RPD values $>2$ are considered adequate for analytical purposes (Sinnaeve et al., 1994; Karoui et al., 2006).

A homemade script implemented in $\mathrm{R}$ software ( $\mathrm{R}$ Development Core Team, 2006) was created following Centner et al. (1996) and Chen et al. (2007). Initially, a random matrix $\mathbf{Z}$ with values between 0 and 1 , and of exactly the same size as the $\mathbf{X}$ matrix, was generated. The $\mathbf{X}$ was a rectangular matrix of order 208 (number of samples) $\times 1,060$ (number of wavelengths). The random matrix $\mathbf{Z}$ was multiplied by a small constant in order to eliminate any possible interaction with the original variables of the $\mathbf{X}$ matrix. The constant value should be lower than the level of inaccuracy of the instrument, which in our case was $10^{-10}$, according to Centner et al. (1996). This step was necessary to avoid large errors during the calculation of eigenvalues. This could also affect the regression coefficients (b) of the original matrix, leading to the erroneous elimination of informative variables. The matrices $\mathbf{X}$ and $\mathbf{Z}$ were then merged into an $\mathbf{X Z}$ matrix of size $n \times 2 p$, where $n$ are the observations and $p$ the wavelengths. A new PLS analysis was carried out on the $\mathbf{X Z}$ matrix through leave-one-out jackknife validation to obtain a matrix containing the coefficients of all the equations used in the validation. A stability criterion (E), as a standardized coefficient, was adopted, according to Centner et al. (1996) and Chen et al. (2007): E $=b j / s(b j)$, for $j=1$ to $p$, where $b j$ is the mean of the regression coefficients vector for the $j$ th variable, and $s(b j)$ is the standard deviation of this vector. The absolute stability coefficient in the $\mathbf{Z}$ matrix was calculated and used as a filter into the original $\mathbf{X}$ matrix. The criterion for the construction of the filter was set to $\mathrm{Ex}<\max (\mathrm{Ez})$, where $\mathrm{Ex}$ are the absolute values on matrix $\mathbf{X}$ and $\mathrm{Ez}$ are the absolute values on matrix $\mathbf{Z}$. Following this criterion, if $j$ variables from the $\mathbf{X}$ matrix exhibited a stability criterion smaller than the maximum obtained for the artificial variables, then the variables were uninformative. Finally, a new PLS model was performed using only the resulting informative wavelengths.

Means (SD) of calibration and validation sets were similar within each data set and they ranged from 3.40 to $3.44{ }^{\circ} \mathrm{SH} / 50 \mathrm{~mL}$ (0.33 to 0.37$)$ and 3.35 to 3.45 ${ }^{\circ} \mathrm{SH} / 50 \mathrm{~mL}$ (0.28 to 0.37 ) for TA, respectively (Table 1), and from 1,148 to $1,164 \mathrm{mg} / \mathrm{kg}$ (129 to 135 ) and 1,125 to $1,188 \mathrm{mg} / \mathrm{kg}$ (123 to 133 ) for $\mathrm{Ca}$, respectively (Table 2).

Figure 1 depicts the most informative wavelengths for TA and Ca extrapolated from the spectrum after the UVE procedure. The number of wavelengths decreased from 520 to 244 and from 520 to 113 for TA and $\mathrm{Ca}$, respectively. The selected peaks were often related to specific chemical bonds: peaks occurring at $1,115,1,146$, and $1,180 \mathrm{~cm}^{-1}$ are related to $\mathrm{C}-\mathrm{O}$ and $\mathrm{C}-\mathrm{C}$ stretching; the peak at $1,331 \mathrm{~cm}^{-1}$ is related to $\mathrm{C}-\mathrm{C}-\mathrm{H}$ stretching; the peak at 1,240 and $1,500 \mathrm{~cm}^{-1}$ can be attributed to the amide group; and peaks at 2,935 and $2,839 \mathrm{~cm}^{-1}$ could be associated with lipids (Hewavitharana and van Brakel, 1997).

Concerning PLS models, the coefficient of determination in calibration $\left(\mathbf{R}_{\mathbf{C}}^{2}\right)$ and root mean square error of calibration $\left(\mathbf{R M S E}_{\mathbf{C}}\right.$ ) ranged from 0.70 to 0.83 and 0.13 to $0.19{ }^{\circ} \mathrm{SH} / 50 \mathrm{~mL}$ for $\mathrm{TA}$, respectively (Table 1 ), and from 0.53 to 0.65 and 76.4 to $89.8 \mathrm{mg} / \mathrm{kg}$ for $\mathrm{Ca}$ content (Table 2). The $R_{C}^{2}$ and $R_{P}^{2}$ were $\geq 0.70$ and $\geq 0.50$ for $\mathrm{TA}$ and $\mathrm{Ca}$, respectively, whereas $\mathrm{RMSE}_{\mathrm{C}}$ and $\mathrm{RMSE}_{\mathrm{P}}$ were $\leq 0.19{ }^{\circ} \mathrm{SH} / 50 \mathrm{~mL}$ for TA (Table 1) and $\leq 96.9 \mathrm{mg} / \mathrm{kg}$ for Ca (Table 2), confirming the ability of MIRS to predict these traits. Overall, RPD values for TA were $>2$, suggesting good predictive ability of the models (Sinnaeve et al., 1994; Karoui et al., 2006), and they were around 1.5 for $\mathrm{Ca}$, indicating moder- 

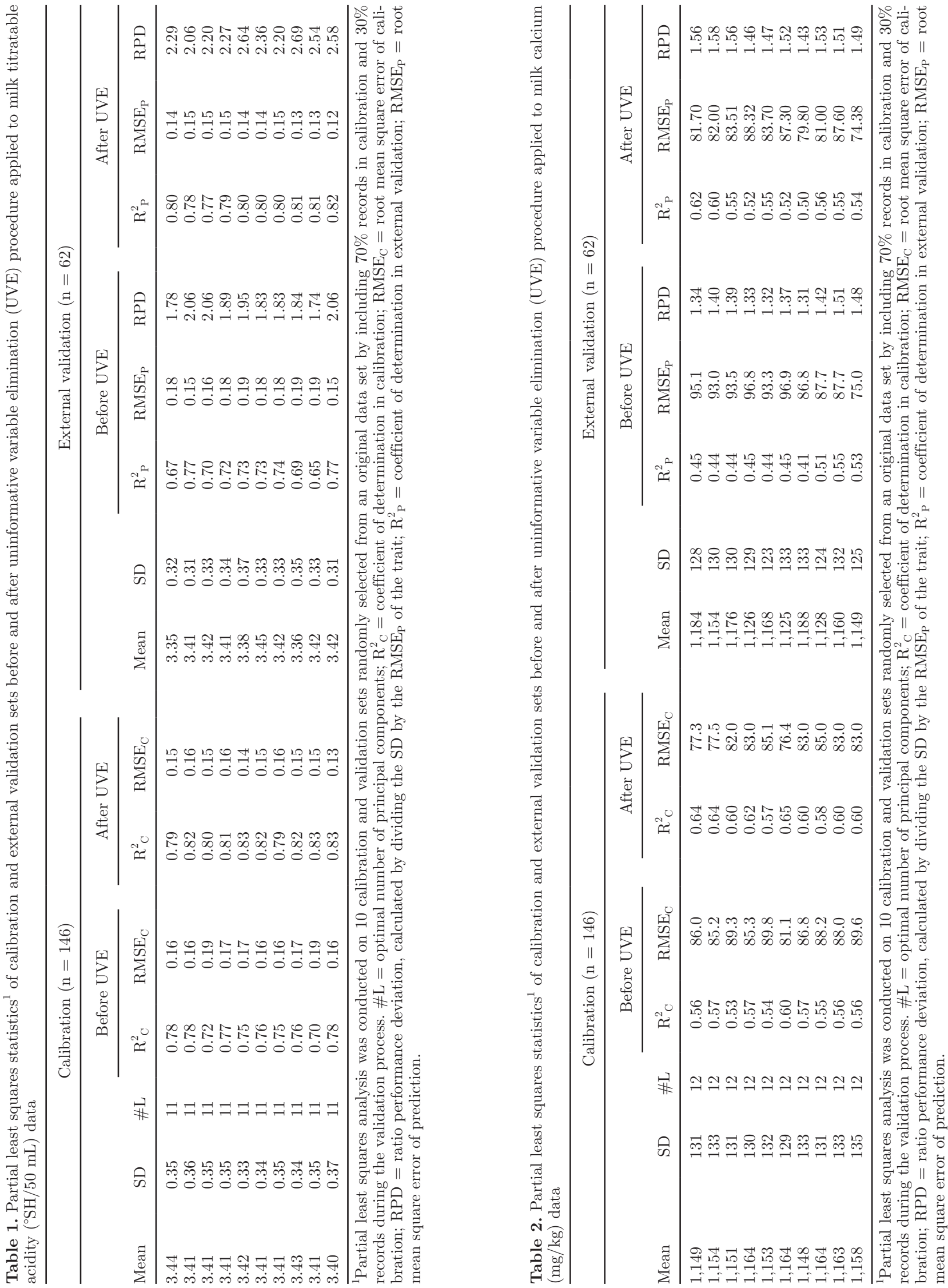
(a)

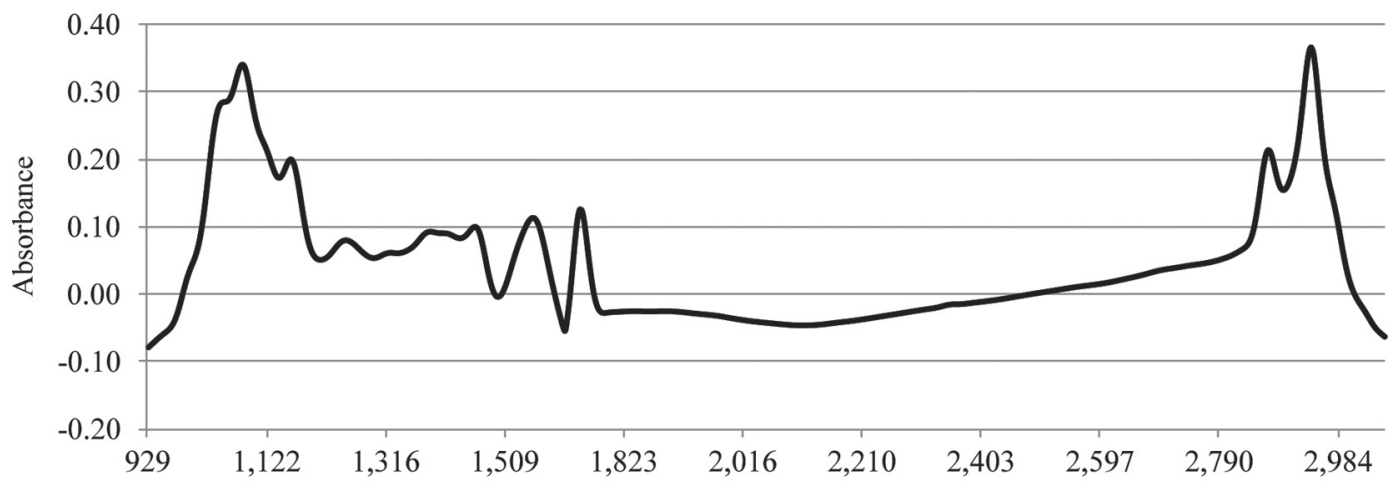

$\left(b_{1}\right)$

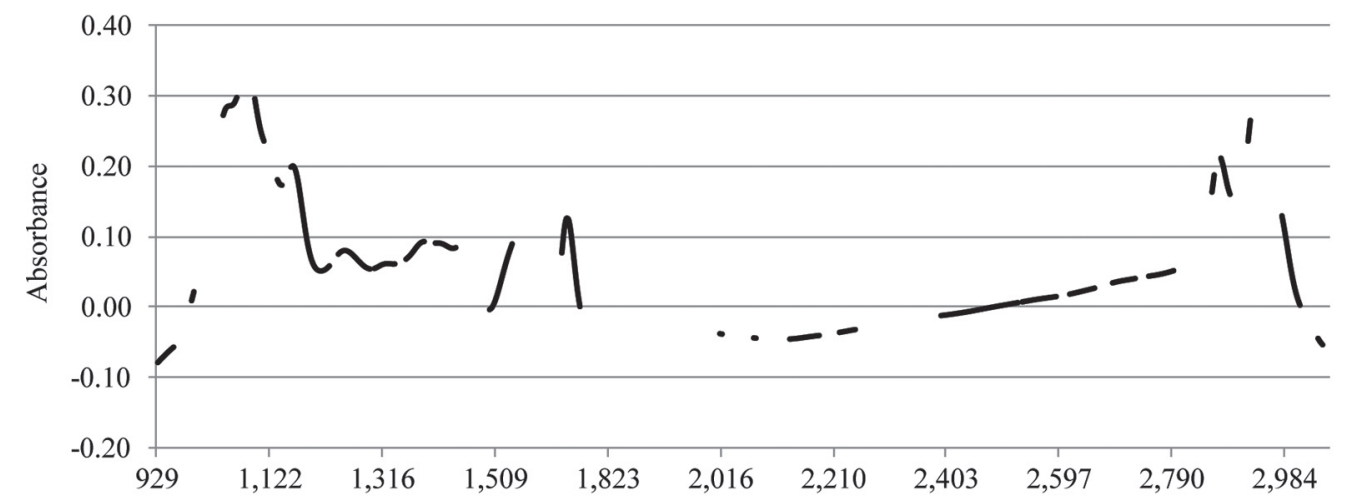

$\left(b_{2}\right)$

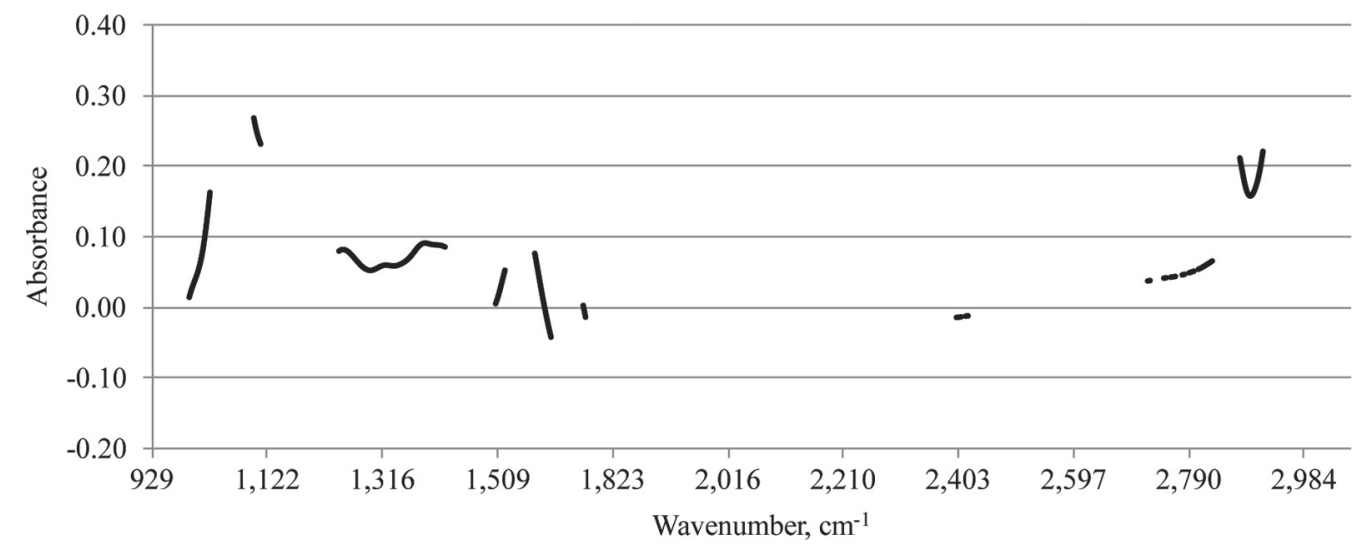

Figure 1. Example of spectra wavenumbers used in the partial least squares analysis (a) before, and (b) after uninformative variable elimination procedure applied to $\left(b_{1}\right)$ titratable acidity, and $\left(b_{2}\right)$ Ca content data.

ate practical utility of the models. The results of TA were better than those of De Marchi et al. (2009), who reported a root mean square error in cross-validation of 0.26 and a coefficient of correlation in cross-validation of 0.80 , and slightly worse than findings of Colinet et al. (2010), who estimated a coefficient of correla- tion in cross-validation of 0.95 for models built using a different reference method for TA than the present study. The Ca results were similar to those reported by Toffanin et al. (2015), who developed MIRS prediction models using the same data but comparing 2 different statistical approaches. 
Prediction models for TA (Table 1) and Ca (Table 2) developed after the UVE procedure exhibited betterfitting statistics than models developed using PLS without UVE. The average improvement of $\mathrm{R}_{\mathrm{P}}^{2}$ and RMSE $_{\mathrm{P}}$, respectively, after UVE was 10 and $10 \%$ for TA, and 20 and $9 \%$ for Ca. Moreover, the variation of $\mathrm{RMSE}_{\mathrm{P}}$ and RPD across PLS analyses conducted on 10 randomly selected data sets was lower when the regression was performed after elimination of uninformative wavelengths, suggesting that models built using the UVE approach were more robust than those developed from PLS analysis without eliminating redundant variables. Finally, removal of more than half of wavelengths from the initial data set reduced the computation time (9 and $1.20 \mathrm{~s}$ before and after the UVE procedure, respectively, using a quad-core 2.40-GHz laptop, with 8 GB of RAM), thus enhancing the efficiency of MIRS models to predict phenotypes.

To our knowledge, this is the first study on the use of UVE to improve MIRS prediction models for milk analysis. Wu et al. (2009) investigated the opportunity to use near-infrared spectroscopy for quality assessment of edible oils, and they reported more parsimonious (e.g., increased speed of calculation) and efficient models to determine $\alpha$-linolenic and linoleic acids using UVE methods to select near-infrared effective variables compared with a conventional PLS model with full spectral data. In a second study, Wu et al. (2012) investigated the feasibility of using near-infrared spectroscopy and MIRS to predict Ca content in powdered milk, and they reported an improvement of prediction-fitting statistics after UVE analysis both for near-infrared and MIRS spectral data.

In conclusion, application of the UVE procedure before PLS analysis is a valid approach to improve the accuracy of prediction models compared with standard PLS, and it greatly reduces computation time. This approach would be particularly useful when data at the population level are available because using UVE can exponentially reduce computation time.

\section{ACKNOWLEDGMENTS}

The authors thank the Breeders Association of Veneto region (ARAV, Padova, Italy) for providing the data used in this study, and Lucia Ancilotto (Department of Agronomy, Food, Natural resources, Animals and Environment, University of Padova, Italy) for technical support. Research was supported by 60A08-0011/13 and 60A08-1929/12 projects of the University of Padova (Padova, Italy). P. Gottardo and M. De Marchi developed the hypothesis of the study; P. Gottardo performed statistical analyses; M. De Marchi and M.
Penasa wrote the first draft of the manuscript; and M. Cassandro reviewed the paper. All authors contributed to the discussion of the work.

\section{REFERENCES}

Anonymous. 1963. Säuregradbestimmung nach Soxhlet-Henkel (SH) [Titratable acidity evaluation with the Soxhlet-Henkel (SH) method]. Milchwissenschaft 18:520.

Centner, V., D.-L. Massart, O. E. de Noord, S. de Jong, B. M. Vandeginste, and C. Sterna. 1996. Elimination of uninformative variables for multivariate calibration. Anal. Chem. 68:3851-3858.

Chen, D., W. Cai, and X. Shao. 2007. Removing uncertain variables based on ensemble partial least squares. Anal. Chim. Acta 598:19-26.

Colinet, F. G., H. Soyeurt, C. Anceau, A. Vanlierde, N. Keyen, P. Dardenne, N. Gengler, and M. Sindic. 2010. Potential estimation of titratable acidity in cow milk using mid-infrared spectrometry. Proc. 37th International Committee for Animal Recording (ICAR) Meeting, Riga, Latvia. Accessed Jul. 21, 2014. http://www.icar. org/Documents/Riga_2010/ppt/Colinet.pdf.

De Marchi, M., C. C. Fagan, C. P. O'Donnell, A. Cecchinato, R. Dal Zotto, M. Cassandro, M. Penasa, and G. Bittante. 2009. Prediction of coagulation properties, titratable acidity, and $\mathrm{pH}$ of bovine milk using mid-infrared spectroscopy. J. Dairy Sci. 92:423-432.

De Marchi, M., M. Penasa, A. Cecchinato, M. Mele, P. Secchiari, and G. Bittante. 2011. Effectiveness of mid-infrared spectroscopy to predict fatty acid composition of Brown Swiss bovine milk. Animal 5:1653-1658.

De Marchi, M., V. Toffanin, M. Cassandro, and M. Penasa. 2013. Prediction of coagulating and noncoagulating milk samples using mid-infrared spectroscopy. J. Dairy Sci. 96:4707-4715.

De Marchi, M., V. Toffanin, M. Cassandro, and M. Penasa. 2014 Invited review: Mid-infrared spectroscopy as phenotyping tool for milk traits. J. Dairy Sci. 97:1171-1186.

Ferrand, M., B. Huquet, S. Barbey, F. Barillet, F. Faucon, H. Larroque, O. Leray, J. M. Trommenschlager, and M. Brochard. 2011. Determination of fatty acid profile in cow's milk using mid-infrared spectrometry: Interest of applying a variable selection by genetic algorithms before a PLS regression. Chemom. Intell. Lab. Syst. 106:183-189.

Hewavitharana, A. K., and B. van Brakel. 1997. Fourier transform infrared spectrometric method for the rapid determination of casein in raw milk. Analyst (Lond.) 122:701-704.

Karoui, R., A. M. Mouazen, É. Dufour, L. Pillonel, E. Schaller, D. Picque, J. de Baerdemaeker, and J.-O. Bosset. 2006. A comparison and joint use of NIR and MIR spectroscopic methods for the determination of some parameters in European Emmental cheese. Eur. Food Res. Technol. 223:44-50.

Leardi, R. 2000. Application of genetic algorithm-PLS for feature selection in spectral data sets. J. Chemometr. 14:643-655.

Li, Y., and J. Jing. 2014. A consensus PLS method based on diverse wavelength variables models for analysis of near-infrared spectra. Chemom. Intell. Lab. Syst. 130:45-49.

McParland, S., G. Banos, B. McCarthy, E. Lewis, M. P. Coffey, B. O'Neill, M. O'Donovan, E. Wall, and D. P. Berry. 2012. Validation of mid-infrared spectrometry in milk for predicting body energy status in Holstein-Friesian cows. J. Dairy Sci. 95:7225-7235.

R Development Core Team. 2006. R: A language and environment for statistical computing. R Foundation for Statistical Computing, Vienna, Austria. http://www.R-project.org/.

Sinnaeve, G., P. Dardenne, R. Agneessens, and R. Bistom. 1994. The use of near infrared spectroscopy for the analysis of fresh grass silage. J. Near Infrared Spectrosc. 2(Spec.):79-84.

Soyeurt, H., P. Dardenne, F. Dehareng, G. Lognay, D. Veselko, M. Marlier, C. Bertozzi, P. Mayeres, and N. Gengler. 2006. Estimating fatty acid content in cow milk using mid-infrared spectrometry. J. Dairy Sci. 89:3690-3695. 
Toffanin, V., M. De Marchi, N. Lopez-Villalobos, and M. Cassandro. 2015. Effectiveness of mid-infrared spectroscopy for prediction of the contents of calcium and phosphorus, and titratable acidity of milk and their relationship with milk quality and coagulation properties. Int. Dairy J. 41:68-73.

Wehrens, R. 2011. Chemometrics With R: Multivariate Data Analysis in the Natural Sciences and Life Sciences. Springer, Heidelberg, Germany.

Williams, P. C. 1987. Implementation of near-infrared technology. Pages 143-167 in Near-Infrared Technology in the Agricultural and Food Industries. 2nd ed. P. C. Williams and K. Norris, ed. American Association of Cereal Chemists, St. Paul, MN.

Wu, D., X. Chen, P. Shi, S. Wang, F. Feng, and Y. He. 2009. Determination of $\alpha$-linolenic acid and linoleic acid in edible oils using near-infrared spectroscopy improved by wavelet transform and uninformative variable elimination. Anal. Chim. Acta 634:166-171.

Wu, D., P. Nie, Y. He, and Y. Bao. 2012. Determination of calcium content in powdered milk using near and mid-infrared spectroscopy with variable selection and chemometrics. Food Bioprocess Technol. 5:1402-1410. 